\title{
Malnutrition in Canadian hospitals
}

\author{
Katherine F. Eckert RD BSc, Leah E. Cahill RD PhD
}

Cite as: CMAJ 2018 October 9;190:E1207. doi: 10.1503/cmaj.180108

1 Malnutrition at hospital admission is common in Canada

In a multicentre study published in 2016, the prevalence of malnutrition on admission to hospital was $45 \%$ in medical and surgical patients who stayed in hospital for longer than two days, as assessed by the Subjective Global Assessment tool. ${ }^{1}$ Comorbid conditions, dependence on adult children for grocery shopping and living alone are independent risk factors for malnutrition at hospital admission. ${ }^{1}$

2 Malnutrition is independently associated with increased length of stay and health care costs in Canadian hospitals Patients who are malnourished have $34 \%-53 \%$ longer hospital stays and cost the health care system $31 \%-55 \%$ more than patients who are well nourished. ${ }^{2}$

The Canadian Nutrition Screening Tool is a quick and effective tool that identifies patients who are at risk of malnutrition This two-item validated questionnaire can be administered by any hospital staff to flag patients who require nutrition care (Box 1). The tool has good sensitivity (> 72.9\%), specificity (85.9\%) and predictive validity for outcomes of length of stay, 30 -day readmission and mortality. ${ }^{3}$

\section{4}

\section{Nutrition care in hospital reduces malnutrition and associated} morbidity and mortality

Once a patient who has been admitted to hospital has been identified as at risk for malnutrition, effective strategies initiated by physicians for reducing malnutrition include consulting a dietitian within 24 hours, monitoring a patient's diet intake, discussing the importance of nutrition with patient or family and providing practical plans for grocery delivery or meal preparation upon discharge. ${ }^{4}$ Nutrition care in hospital can reduce infections, pressure sores, length of stay, falls, fractures, hospital readmission and mortality. ${ }^{4}$

\section{Identification and early intervention in primary care can reduce malnutrition}

A recent systematic review of 26 randomized clinical trials concluded that primary care referrals of patients at risk for malnutrition to dietitians for nutrition assessment and intervention are effective for improving diet intake and quality. ${ }^{5}$ Physician encouragement of nutrition treatment and counselling substantially advances a patient's success with healthy eating. ${ }^{6}$ Malnutrition resources for physicians are available in Appendix 1 (available at www.cmaj.ca/lookup/suppl/doi:10.1503/ cmaj.180108/-/DC1).
Box 1: The Canadian Nutrition Screening Tool to identify patients who are at risk of malnutrition ${ }^{3}$

Ask the patient the following questions: ${ }^{*}$

- Have you lost weight in the past six months without trying to lose this weight?

- Have you been eating less than usual for more than a week?

Two "yes" answers indicate nutrition risk.

*If the patient is unable to answer the questions, a knowledgeable informant can be used to obtain the information. If the patient is uncertain regarding weight loss, ask if clothing is now fitting more loosely.

†If a patient reports a weight loss but gained it back, consider it as no weight loss.

\section{References}

1. Allard JP, Keller H, Jeejeebhoy KN, et al. Malnutrition at hospital admission - contributors and effect on length of stay. A prospective cohort study from the Canadian Malnutrition Task Force. JPEN J Parenter Enteral Nutr 2016;40:487-97.

2. Curtis LJ, Bernier P, Jeejeebhoy K, et al. Costs of hospital malnutrition. Clin Nutr 2017;36:1391-6.

3. Laporte $\mathrm{M}$, Keller $\mathrm{HH}$, Payette $\mathrm{H}$, et al. Validity and reliability of the new Canadian Nutrition Screening Tool in the 'realworld' hospital setting. Eur J Clin Nutr 2015;69:558-64.

4. Tappenden KA, Quatrara B, Parkhurst ML, et al. Critical role of nutrition in improving quality of care: an interdisciplinary call to action to address adult hospital malnutrition. JPEN $J$ Parenter Enteral Nutr 2013;37:482-97.

5. Mitchell LJ, Ball LE, Ross LJ, et al. Effectiveness of dietetic consultations in primary health care: a systematic review of randomized controlled trials. J Acad Nutr Diet 2017;117:1941-62.

6. Endevelt R, Gesser-Edelsburg A. A qualitative study of adherence to nutritional treatment: perspectives of patients and dietitians. Patient Prefer Adherence 2014;8:147-54.

\section{Competing interests: None declared.}

This article has been peer reviewed.

Affiliations: Departments of Community Health and Epidemiology (Eckert), and Medicine (Cahill), Dalhousie University, Halifax, NS; Department of Nutrition (Cahill), Harvard T.H. Chan School of Public Health, Boston, Mass.

Correspondence to: Leah Cahill, leah.cahill@dal.ca 